\title{
DISCUTINDO AS PRÁTICAS DE ENSINO: RESOLUÇÃO DE PROBLEMAS E INVESTIGAÇÃO MATEMÁTICA
}

\section{DISCUSSING THE PRACTICES OF TEACHING: SOLVE-PROBLEMS AND MATHEMATIC INQUIRY}

\author{
Sani de Carvalho Rutz da Silva* e Ana Cristina Schirlo** \\ Universidade Tecnológica Federal do Paraná $\left({ }^{*}\right)$ \\ Programa de Pós-Graduação em Ensino de Ciência e Tecnologia \\ E-mail: sani@utfpr.edu.br \\ Secretaria de Estado de Educação do Paraná $\left({ }^{* *}\right)$ \\ Instituto de Educação Professor Cézar Prieto Martinez \\ E-mail: acschirlo@seed.pr.gov.br
}

\section{Resumo}

Com as mudanças ocorridas no mundo nas últimas décadas, muitos paradigmas estão sendo derrubados. Fato que vem gerando alterações na forma de ver e de analisar o mundo atual. Nesse contexto, esse ensaio teórico, de cunho qualitativo, tem por objetivo promover reflexões sobre a resolução de problemas e a investigação matemática, como práticas de ensino da Educação Matemática. Para encerrar é relevante frisar que a escola tem por escopo formar estudantes capazes de compreender o mundo e dele participar de forma crítica, criativa e ativa. $\mathrm{O}$ estudo aponta que situar o ensino da Matemática nos aportes das práticas de ensino resolução de problemas e investigação matemática é relevante pois quanto maior for a quantidade de informações sobre as práticas de ensino que se fazem presentes nas salas de aula de Matemática, mais subsídios metodológicos os professores terão para auxiliá-los na construção do processo de ensino e aprendizagem.

Palavras-chave: Educação Matemática; Resolução de problemas; Investigação matemática.

\begin{abstract}
With the changes in the world in recent decades, many paradigms are being overturned. Fact that has generated changes in the way of seeing and analyzing the current world. In this context, this theoretical essay, a qualitative, aims to promote reflection on solve-problems and mathematic inquiry, as teaching practices in Mathematics Education. In closing it is important to note that the school has the scope to train students capable of understanding the world and his part in a critical, creative and active. The study indicates that the situating mathematics teaching contributions in teaching practices and solve-problems mathematic inquiry is important because the larger the amount of information about teaching practices that are present in the classrooms of Mathematics, more subsidies methodological teachers will have to assist them in building the process of teaching and learning.
\end{abstract}

Keywords: Mathematic Education; Solve-problems; Mathematic inquiry. 


\section{INTRODUÇÃO}

As mudanças ocorridas no mundo nas últimas décadas estão derrubando paradigmas. Esse fato vem gerando alterações na forma de ver e de analisar esse mundo novo. Assim, a sociedade atual passa por mudanças nas áreas: econômica, política, social, tecnológica, educacional entre outras.

Acredita-se que essas mudanças exibem um mundo globalizado cheio de exigências e que, para satisfazê-las, o cidadão precisa experienciar situações de (re)construção dos conhecimentos que o auxilia à desenvolver habilidades cognitivas, proporcionando seu letramento frente às exigências do mundo moderno.

Nesse contexto, entende-se que há um momento de transição, de crise paradigmática nas diversas áreas do conhecimento humano, o que vem exercendo modificações em todos os campos de atuação.

Essa visão em torno da forma de viver faz com que a sociedade se expanda e que o homem não possa mais agir de forma independente. Dessa maneira, a sobrevivência de um indivíduo dentro da sua espécie requer, além de aptidões físicas, o acesso a informações e a meios para decodificá-las. Também, exige-se uma capacidade para processar e tomar decisões perante as novas informações captadas pelos sentidos.

Cabe ressaltar que os seres humanos vivem diariamente cercados por computadores, caixas registradoras, calculadoras, banco eletrônico, máquinas de informação dentre tantos outros artefatos tecnológicos que se utilizam de números, gráficos e tabelas para funcionarem.

Porém, quando não dominam esses eletrônicos sentem-se deslocados e constrangidos ante tanta tecnologia. Então, a Matemática passa a atuar como uma ferramenta para que o homem possa dominar os eletrônicos e resolver muitos dos problemas encontrados em seu cotidiano, como por exemplo, as implicações no mundo do trabalho.

Os Parâmetros Curriculares Nacionais - PCN - de Matemática (BRASIL, 1998) apontam que para ocorrer inserções dos cidadãos no mundo do trabalho, no mundo das relações sociais é importante 
que a Matemática desempenhe, no currículo, seu papel na formação de capacidades intelectuais, na estruturação do pensamento, na agilização do raciocínio do aluno, na sua aplicação a problemas, situações da vida cotidiana e atividades do mundo do trabalho e no apoio à construção de conhecimentos em outras áreas curriculares.

Ainda, segundo o exposto no PCN de Matemática (BRASIL, 1998), a disciplina escolar Matemática, desempenha um papel de suma importância na formação do pensamento - lógico e reflexivo - e do conhecimento, na agilização do raciocínio, assim funciona como um instrumento essencial para a construção de conhecimentos em outras áreas do saber, pois interfere fortemente na formação de capacidades intelectuais e na ativação do raciocínio indutivo - no intuito de buscar regularidades para fazer generalizações - e, no raciocínio dedutivo - para determinar ou verificar resultados significativos.

Assim, a importância da Matemática para a compreensão e participação do homem nas sociedades modernas é visivelmente crescente e imprescindível. Logo, a habilitação dos seres humanos à compreensão dos conceitos matemáticos básicos passa a ser um dos grandes desafios impostos à escola frente ao fenômeno da globalização.

Torna-se, portanto, necessário a construção de caminhos e projetos, emergentes das necessidades e interesses dessa sociedade que deseja a formação de um cidadão apto a enfrentar os desafios inerentes de um país em desenvolvimento.

Para tanto, educadores se reúnem em congressos, simpósios, encontros, entres outros eventos científicos, para discutirem sobre a didática e as práticas de ensino da Matemática.

Miguel, Garnica, Igliori e D’Ambrósio (2004, p. 80-89), questionam se as "práticas sociais produtoras de cultura matemática seriam incomensuráveis com práticas sociais produtoras de cultura educativa relativa à cultura matemática?".

Essa preocupação é pertinente tanto à modernização das aulas quanto à atualização do currículo escolar da Matemática. De acordo com Schubring (1999) a Matemática é a disciplina escolar que 
realizou as mudanças curriculares visando uma melhora no processo de ensino e aprendizagem, deflagrando um movimento internacional de reformulação curricular.

Bicudo (2005, p. 30) relata que "é necessário uma didática que inicie o aluno na produção do conhecimento matemático, permitindo-Ihe ser sujeito de sua ação, já que no tempo de que dispõe a escola, não seria mesmo possível responder a todas as suas perguntas e dúvidas".

Ressalta-se que aprender Matemática não é apenas conhecer um conjunto de determinadas informações, mas ter também capacidade de estabelecer relações mentais com suas aplicações.

Wood (1996) aponta a necessidade de que a Matemática desenvolvida na sala de aula constitua uma atividade com significado para os alunos, considerando que, para isso, é essencial que se crie um ambiente em que eles interajam uns com os outros, em que possam exprimir os seus pensamentos e em que questionem as idéias apresentadas pelos colegas.

Diante de uma miscelânea de modos e maneiras de se ensinar os conteúdos matemáticos nas salas de aula, o PCN de Matemática (BRASIL, 1998, p. 37) afirma que, "os professores precisam ter clareza de suas próprias concepções sobre a Matemática, uma vez que a prática em sala de aula, as escolhas pedagógicas, a definição de objetivos e conteúdos de ensino e as formas de avaliação estão intimamente ligadas a essas concepções".

Assim, com um repensar sobre o assunto, o professor pode iniciar um processo de mudança conceitual, de um modelo para outro, e procurar meios para solucionar a falha no ensino da Matemática, buscando práticas de ensino que permitam representar sua ação de educador com todos os seus múltiplos objetivos, tentando, assim novas formas de aprendizagem, com a finalidade de conduzir o estudante a desenvolver um compromisso e responsabilidade, competências e atitudes que o capacitem aultrapassar obstáculos de toda ordem, principalmente os político-sócio-culturais, para a consecução de seu objetivo primeiro: a formação de pessoas para o exercício pleno de sua cidadania.

Ressalta-se que é consensual a ideia que não existe um caminho que possa ser identificado como único e melhor para o ensino de qualquer disciplina, em particular, da Matemática. No entanto, 
conhecer diversas possibilidades de trabalho em sala de aula é fundamental para que o professor construa sua prática (BRASIL, 1998, p. 42).

A partir desse apontamento, decorre a necessidade de investigar as práticas de ensino pertencentes à Educação Matemática. Saliente-se que nesse momento será discutida a resolução de problemas e a investigação matemática, pois se entende que elas em conjunto são práticas de ensino que permitem o desenvolvimento de atividades atrativas e que auxiliam os estudantes a enfrentarem as realidades tecnológicas e os desafios impostos pela atual sociedade.

Nesse contexto, traçou-se um ensaio teórico de cunho qualitativo, visando discutir a resolução de problemas e a investigação matemática, como práticas de ensino da Educação Matemática que atendem às exigências do processo ensino e aprendizagem do mundo globalizado.

\section{EDUCAÇÃO MATEMÁTICA}

É de amplo conhecimento que na área do saber matemático, educadores e pesquisadores se reúnem em eventos científicos, para discutirem diversos temas relevantes para o processo de ensino e aprendizagem da Matemática. E, que como consequência dessas discussões, a partir da década de 70, surgiu na França a Educação Matemática.

Kilpatrick (1992, p. 34-35) aponta três fatores determinantes para o surgimento da Educação Matemática enquanto campo profissional e científico.

10 Fator: preocupação dos próprios matemáticos e de professores de Matemática sobre a qualidade da divulgação e socialização das ideias matemáticas às novas gerações. Essa preocupação dizia respeito tanto à melhoria de suas aulas quanto à atualização e modernização do currículo escolar da Matemática.

2ㅇ Fator: iniciativa das universidades europeias, no final do século XIX, em promover formalmente a formação de professores secundários. Isso 
contribuiu para osurgimento de especialistas universitários em ensino de Matemática.

30 Fator: estudos experimentais realizados por psicólogosamericanos e europeus, desde o início do século XX, sobre o modo como as crianças aprendiam a Matemática.

Desse modo, enquanto campo profissional e científico, o surgimento da Educação Matemática, acredita-se ter sido atribuído às preocupações de matemáticos e de professores de Matemática a respeito da qualidade da exposição e da socialização de ideias matemáticas.

Nesse sentido, a Educação Matemática discute o problema de se saber o alcance e as formas que as práticas sociais de caráter educativo participam, de forma ativa e criativa, na produção da cultura matemática de um modo geral.

Porém, para Garnica (1999, p. 61), "a educação matemática pode ser vista como um "movimento", o que implica aceitar que, desde o primeiro instante que se decidiu ensinar a alguém alguma coisa chamada "matemática", uma ação de educação matemática começou a manifestar-se".

Nesse viés, a Educação Matemática conquistou espaço nos últimos anos como área interdisciplinar, pois procura em outras áreas do conhecimento - Psicologia, Filosofia, Sociologia, História, Antropologia - subsídios para ajudar a formação do cidadão para o século XXI.

Acrescenta-se que esses subsídios se fazem necessários para que o aluno sinta-se apto a enfrentar os desafios frequentes da sociedade científica e tecnológica na qual está inserido.

No entender de D’Ambrósio (1986, p. 35) ,“a Educação Matemática poderia ser caracterizada como uma atividade multidisciplinar, que se pratica com um objetivo geral bem específico transmitir conhecimentos e habilidades matemáticas - através dos sistemas educativos (formal, não formal e informal)".

Dessa forma, a da Educação Matemática passa a ser entendida como uma forma de expressão, isto é, como uma linguagem que é produzida e utilizada socialmente como representação do real e da 
multiplicidade defenômenos propostos pela realidade, possibilitando ao aluno a apropriação do conhecimento matemático para ser usado como instrumento necessário ao exercício da cidadania.

Sob seu ponto de vista, Vianna (2003, p. 53) acredita que

a educação matemática não sobreviverá se não admitir essa múltipla interação [entre a Educação Matemática e sociedade], correndo o risco de se ver reduzida a uma didática da matemática ou, o que é pior, ao ensino da matemática e que ela é instituída pela sociedade e como, reciprocamente, atua sobre os indivíduos permeando relações de poder, crenças, visões de mundo.

Essa preocupação é pertinente tanto à melhoria das aulas quanto à atualização e modernização do currículo escolar da Matemática. Machado (1997) afirma a importância de se repensar o ensino da Matemática em um sentido globalizante, que transcenda o tecnicismo de todas as ordens, que possa inscrever tal ensino numa perspectiva de ação transformadora.

Nesse contexto, a Educação Matemática como componente curricular deve ser compreendida pelos professores como objeto de cultura, como ferramenta de trabalho, que está inserida no processo histórico-social onde ele é produzido, ou seja, no cotidiano escolar.

Acredita-se que o ensino e a aprendizagem da Matemática abarcam discussões de pedagogia em sentido amplo, tratando da filosofia da educação, da históriada matemática e de tantos outros aspectos que cercam a educação matemática, de modo que a ela seja tida como uma região de inquérito que mantém interseções em educação e em matemática, na busca de sua identidade própria.

A leitura dos expostos nos conduz ao entendimento que alguns autores, concebem a Educação Matemática como área de conhecimento teórico-prática, outros como um movimento que se institui no instante mesmo em que algo a que chamamos Matemática ocorre num contexto de ensino e aprendizagem.

Neste momento, pode-se falar que - embora ainda em construção - o objeto de estudo da Educação Matemática versa nas diferentes relações e determinações entre ensino, aprendizagem e conhecimento matemático, sem priorizar o estudo de um desses elementos da tríade. 
Assim, a Educação Matemática pretende não somente ajudar os estudantes a aprenderem certas formas de conhecimento e de técnicas, mas também convidá-los a uma reflexão acerca do modo como essas formas de conhecimento e de técnicas devem ser aprendidas. Para tanto, o aluno não deve perder tempo resolvendo mecanicamente operações matemáticas, mas investir na resolução criativa de situações problemas.

É consensual a idéia que não existe um caminho que possa ser identificado como único e melhor para o ensino de qualquer disciplina, em particular, da Matemática. No entanto, conhecer diversas possibilidades de trabalho em sala de aula é fundamental para que o professor construa sua prática (BRASIL, 1998, p. 42).

Dentre as várias práticas de ensino: Etnomatemática, Modelagem Matemática, História da Matemática, Resolução de Problemas, Investigação Matemática, pertinentes a Educação Matemática, dar-se-á ênfase à Resolução de Problemas e a Investigação Matemática, pois o PCN de Matemática (BRASIL, 1998) expõe que o ensino de Matemática precisa proporcionar ao aluno vivências de situações próximas e que the permitam reconhecer a diversidade ao seu redor, podendo assim atuar e compreender as situações vivenciadas no cotidiano.

\subsection{Resolução de problemas}

A resolução de problemas é um caminho para o ensino de Matemática que vem sendo discutido ao longo das últimas décadas e apresenta concepções que evoluíram desde os apontamentos feitos por Polya (1949) até os apontamentos recentes.

Nesse sentido, Schroeder e Lester (1989) apontam três concepções de abordar a resolução de problemas, sendo elas: ensinar a resolução de problemas, ensinar sobre resolver problemas e ensinar Matemática através da resolução de problemas.

Cabe destacar que ensinar a resolução de problemas é uma concepção que vem do modelo de Polya (1949), ou seja, que resolver um problema era encontrar um caminho onde nenhum outro é 
conhecido. Assim, resolver problemas era a realização específica da inteligência e, que esta era tida como um dom específico do homem.

Já, ensinar a resolução de problemas é ensinar Matemática para resolver problemas, pois aprender Matemática é tido como um sinônimo de ser capaz de usá-la.

$E$, ensinar Matemática através da resolução de problemas é um processo de ensino-aprendizagem que começa com uma situação-problema que expressa aspectos chaves do tópico matemático, conduzindo a apresentar soluções para o mesmo.

É nesse sentido que a partir dos anos 80, o National Council of Supervisor sof Mathematics( NCSM), apresentou o documento An Agenda for Action, apontando a resolução de problemas como um dos doze componentes da Matemática Fundamental. Este documentotambém afirma que aprender a resolver problemas é a razão fundamental para estudar Matemática, pois resolver problemasconsiste em aplicar conhecimentos previamente adquiridos a situações novas e não rotineiras (NCSM, 1989).

E, no Brasil, na década de 90, foi lançado o PCN de Matemática (BRASIL, 1998) para as oito séries do Ensino Fundamental, o qual aponta a resolução de problemas, na perspectiva indicada pelos educadores matemáticos, possibilitando aos alunos mobilizar seus conhecimentos e desenvolver sua capacidade para gerenciar as informações que estão ao seu alcance.

Ou seja, por meio da resolução de problemas, os alunos terão oportunidade de ampliar seus conhecimentos acerca de conceitos e procedimentos matemáticos bem como de ampliar a visão que têm dos problemas, da Matemática, do mundo em geral e desenvolver sua autoconfiança (BRASIL, 1998, p. 40).

O PCN de Matemática (BRASIL, 1998, p. 42), também pontua que resolver um problema não se resume em compreender o que foi proposto e em dar respostas aplicando procedimentos adequados, mas aprender a dar uma resposta correta, que tenha sentido, pode ser suficiente para que ela seja aceita e até seja convincente. Além disso, é necessário desenvolver habilidades que 
permitam provar os resultados, testar seus efeitos, comparar diferentes caminhos para obter a solução.

Nessa forma de trabalho, a importância da resposta correta cede lugar à importância do processo de resolução, pois o pensar e o fazer se mobilizam e se desenvolvem quando o indivíduo está engajado ativamente no enfrentamento de desafios.

Logo, a resolução de problemas não é uma atividade para ser desenvolvida em paralelo ou como aplicação da aprendizagem, mas uma orientação para a aprendizagem, pois proporciona o contexto em que se pode aprender conceitos, procedimentos e atitudes matemáticas. Nesse entender, a resolução de problemas sugere novas formas de trabalho em sala de aula.

Van de Walle (2001), Onuchic (2003) e Allevato (2005) têm experimentado o processo de resignificação que possibilita considerar um problema como ponto de partida e orientação para a aprendizagem de novos conteúdos e conceitos matemáticos, tornando assim, a resolução de problemas uma prática de ensino da Matemática.

Onuchic e Allevato (2005), subliam que o ensino da Matemática através da resolução de problemas, coloca o foco da atenção dos alunos sobre ideias e sobre o "dar sentido", pois ao resolver problemas, os alunos necessitam refletir sobre ideias que estão inerentes e/ou ligadas ao problema. Nesse entender, ensinar matemática através da Resolução de Problemas pode ser considerado uma prática de ensino, que conduz o estudante a apresentar soluções usando sua própria linguagem.

Para enfatizar o exposto, ressalta-se que Onuchic (1999) elaborou um roteiro para dinamizar a metodologia de trabalho ensino-aprendizagem-avaliação de matemática através da resolução de problemas, no qual constam os seguintes tópicos: formar grupos, o papel do professor, resultados na lousa, plenária, análise dos resultados, consenso e formalização.

Convém acrescentar que no tópico "formar grupos" sugere-se que se entregue uma atividade ou situação-problema para os alunos resolverem de modo que o processo seja compartilhado e cooperativo dando a oportunidade de aprender uns com os outros. Assim, "o papel do professor" 
muda de comunicador do conhecimento para o de observador, organizador, consultor, mediador, interventor, controlador, incentivador da aprendizagem.

É pertinente expor os "resultados na lousa" de modo a anotar os resultados obtidos pelos grupos quer sejam certo ou errado e aqueles feitos por diferentes caminhos. Esse fato conduz a "plenária", ou seja, a uma assembleia com todos os alunos, pois como todos trabalham sobre o mesmo problema, ficam ansiosos quanto a seus resultados.

Logo, a "análise dos resultados" conduz ao trabalhados dos pontos de dificuldade, sendo que o aspecto exploração é bastante considerado nesta análise até que se alcance o "consenso" sobre o resultado pretendido e, finalmente aconteça a "formalização" por meio de umas íntese daquilo que se objetivava aprender a partir do problema, colocando as devidas definições, identificando as propriedades e fazendo as demonstrações necessárias para sanar as dúvidas ainda existentes.

Onuchic (2004), Krulik e Rudnick (2005), salientam que para ensinar matemática através da resolução de problemas, o professor ao propor um problema aos alunos, deve refletir e analisar os fatos ocorridos durante a resolução e os resultados didáticos obtidos ou não: adequação do problema, processos de resolução, diferentes soluções obtidas, grau de dificuldade, possibilidade de extensão de conteúdos matemáticos e de geração de novos problemas.

Onuchic e Allevato (2005) complementam o exposto, afirmando que o ensino-aprendizagem de um tópico matemático deve sempre começar com uma situação-problema que expressa aspectos chave desse tópico e técnicas matemáticas devem ser desenvolvidas na busca de respostas razoáveis à situação-problema dada.

Logo, o aprendizado pode ser visto como um movimento do concreto - um problema do mundo real que serve como exemplo do conceito ou da técnica - para o abstrato - uma representação simbólica de uma classe de problemas e técnicas para operar com estes símbolos - pois, a compreensão de Matemática por parte dos estudantes envolve a ideia de que compreender é essencialmente relacionar. 
Esta posição baseia-se na observação de que a compreensão aumenta quando o estudante é capaz de relacionar uma ideia matemática a um grande número ou a uma variedade de contextos, relacionar um dado problema a um grande número de ideias Matemáticas implícitas nele.

Nesse sentido, as tarefas precisam ser planejadas ou selecionadas a cada dia, considerando a compreensão dos alunos e a necessidade do currículo. É frequentemente difícil planejar mais do que alguns poucos dias de aulas à frente. Se há um livro-texto tradicional, será preciso, muitas vezes, fazer modificações.

Assim, a resolução de problemas propõe que o problema matemático instigue o aluno e o leve ao movimento de aprendizagem. E, logo após a solução de vários problemas, os conceitos matemáticos - definições, propriedades, entre outros - sejam sistematizados pelo professor, utilizando-se do rigor e do formalismo característicos da matemática.

Tudo isso, para que a situação-problema seja o ponto de partida da atividade matemática e não a definição, que a situação-problema venha a expressar aspectos chaves para o conceito que se quer estudar, levando assim, a aluno a interpretar o enunciado da questão, estruturar a situação que lhe está sendo apresentada e utilizar o que aprendeu para resolver outros problemas, para que ele torne-se ativo, assumindo uma postura de investigador e construtor do seu próprio conhecimento.

\subsection{Investigação matemática}

Sabe-se que a Educação Matemática tem como objetivo criar estratégias para que o aluno gere e construa compreensão, atingindo a promoção de aprendizagens em um processo de desenvolvimento intelectual.

Assim, "em Matemática, compreender uma ideia é conectar o significado dessa ideia com o significado de outra ideia em Matemática, em outro domínio do conhecimento, ou na vida diária". (ARCAVI, 1998, p. 83). 
No entanto, segundo Wood (1996), para que essa conexão seja efetivada, a Matemática desenvolvida na sala de aula, tem a necessidade de construir uma atividade com significado para os alunos.

Nesse sentido, aprender Matemática não é simplesmente compreender a Matemática já feita, mas ser capaz de fazer investigação de natureza matemática, ao nível adequado a cada grau de ensino. (BRAUMANN apud PONTE, 2003, p. 19).

Porém, para que isso aconteça é fundamental a criação de um ambiente interativo, onde se possa exprimir os seus pensamentos e questionamentos. Então, acredita-se que para isso acontecer, o professor deve proporcionar um ambiente de trabalho que estimule o aluno a criar, comparar, discutir, rever, perguntar e ampliar ideias, logo esse ambiente é o de uma comunidade de investigação.

De acordo com Ponte (2003), as investigações acontecem em um processo pedagógico constituído de momentos, os quais apontam o potencial das práticas de ensino que estão pautadas por um fazer matemático como um processo em construção, que exige do aluno uma participação ativa na proposição de questões, na elaboração, testagem e comprovaçãode hipóteses.

Ponte (1999) ainda explicita sinteticamente, que a investigação matemática é sempre uma viagem ao desconhecido, que começa com uma pista ou com uma ideia e segue semelhante a um detetive, exercitando a imaginação e mostrando como a Matemática pode ser uma viagem de descobertas.

Neste sentido, a investigação matemática se diferencia das demais atividades de ensinoaprendizagem pela ênfase dada ao processo, pois nela as situações de ensino "são mais abertas - a questão não está bem definida no início, cabendo a quem investiga um papel fundamental na sua definição". (PONTE, 2003, p. 23).

Assim, no âmbito da investigação Matemática, questões propostas pelo professor ou pelos alunos podem ser o ponto de partida, logo o professor deixa de ser um transmissor de conhecimento e o aluno deixa de ser um receptor de conhecimento (PONTE, 2003). 
Então, a Matemática deixa de ser um assunto onde tudo está pronto, onde nada mais pode ser discutido e passa a apresentar muitos caminhos. Nesse contexto, segundo Ponte (1999), a investigação matemática é uma prática de ensino-aprendizagem, que salienta uma maneira de viver na sala de aula, com negociações e estabelecimento de normas entre alunos e professor.

Cabe apontar que essa prática faz uso de aulas investigativas, tarefas investigativas e atividades investigativas. (PONTE, 2003).

A primeira delas, ou seja, as aulas investigativas são aquelas em que os alunos são mobilizados a realizar investigações matemáticas em sala de aula. É pertinente esclarecer que em contextos de ensino e aprendizagem,

investigar não significa necessariamente lidar com problemas muito sofisticados na fronteira do conhecimento. Significa, tão só, que formulamos questões que nos interessam para as quais não temos resposta pronta, e procuramos essa resposta de modo tanto quanto possível fundamentado e rigoroso. (PONTE; BROCADO; OLIVEIRA, 2003, p. 9).

Já, as tarefas investigativas são propostas de trabalho que, por seu grau de abertura a múltiplas abordagens e problematizações, possibilitam a realização de atividades investigativas por parte dos alunos (PONTE, 2003). Ou seja, são tarefas pedagógicas e escolares que promovem a problematização de conceitos matemáticos e a resolução de problemas, visando à formação cultural, intelectual e humanística dos alunos.

E, as atividades investigativas são aquelas que podem se apresentar como um instrumento importante para desestabilizar o sistema de crenças que por vezes parece engessar o desenvolvimento do pensamento matemático, trazendo potencialmente a possibilidade de propiciar ao estudante ter experiências matemáticas. (PONTE, 2003).

Segundo Mason (1996), a investigação matemática, em sala de aula, pode ser fruto da curiosidade de um aluno ou de um grupo de alunos, a respeito de um determinado tema ou problema. Mas, também pode ser proposta pelo professor. 
Porém, para que a tarefa possa desencadear atividades investigativas é necessário que ela instigue a curiosidade do aluno, entusiasmando-o e fazendo com que ele recorra a conhecimentos já adquiridos, os quais apresentam ligações com o conteúdo a ser adquirido.

Para tanto, as situações abertas, cujas questões não estão completamente formuladas, contemplam o desenvolvimento de uma atividade investigativa, pois conduzem o aluno ao envolvimento de uma atividade.

Portanto, Ponte (2003) afirma que em uma aula aos moldes da investigação matemática, o trabalho investigativo distingue de um modo geral, três etapas fundamentais: a formulação da tarefa, o desenvolvimento do trabalho e o momento de síntese e conclusão final.

No início da atividade, o professor procura envolver os alunos no trabalho, propondo-lhes a realização de uma tarefa. Durante a atividade, ele verifica se os educandos estão trabalhando de modo produtivo, formulando questões, representado a informação dada, ensaiando e testando conjecturas e procurando justificá-las. Na fase final, o professor procura saber quais as conclusões a que os alunos chegaram como as justificam e se tiram implicações interessantes (CHRISTIANSEN; WALTHER, 1986; MASON, 1996; CHAPMAN, 1997).

Também é pertinente expor que a investigação matemática procura veicular os seguintes valores e princípios: (i) investigação e atividade são meios através dos quais o conhecimento pode ser produzido; (ii) professores e alunos são produtores de conhecimento; (iii) negociação de significados e tomadas de decisão são fatores importantes na construção e na apropriação do conhecimento pelos alunos; (iv) os alunos devem ser estimulados no sentido da conquista da autonomia intelectual (PONTE, 2003).

Nesse entendimento, o professor tem que apresentar aos alunos informações sobre os conceitos, procedimentos e notações matemáticas. Ou seja, fornecer a fundamentação teórica necessária para o desenvolvimento do trabalho.

Segundo Lampert (1990), o professor deve colocar a fundamentação à medida que se ensina fazer Matemática, integrando algumas informações sobre ferramentas e convenções matemáticas. 
Logo, o professor tem que manter um diálogo com os alunos enquanto eles vão trabalhando na tarefa proposta, e no final cabe-lhe conduzir a discussão coletiva. E, ao longo de todo esse processo, ele precisa criar um ambiente propício à aprendizagem, estimular a comunicação entre os alunos e assumir uma variedade de papéis que favoreçam a sua aprendizagem.

Ainda, cabe ao professor servir de modelo aos alunos no que se refere ao modo de trabalhar em Matemática.

Mason (1996) expõe que o professor deve ter presente que em sala de aula, ele é um representante da comunidade dos matemáticos e que, consequentemente, a forma como se envolve nos problemas constitui um modelo para os alunos. Pois, entende-se que ao observar o professor a raciocinar matematicamente, os alunos desenvolverão uma apreciação da importância e do valor dos processos em que estão envolvidos e dos resultados que vão obtendo.

Dessa forma, Ponte (1999) explica que a realização de uma investigação, exige que o professor apóie seus alunos a progredirem no trabalho. Mas, para isso ele há de considerar se a exploração matemática da tarefa proposta - durante a atividade - está levando os alunos atrabalharem de modo produtivo e, se a gestão da situação didática está promovendo a participação dos alunos na atividade da aula.

Já, na conclusão do trabalho investigativo, cabe ao professor saber quais foram às conclusões que seus estudantes chegaram, como as justificaram e se tiraram implicações interessantes. Entende-se que esse é um bom momento para promover uma visão geral dos vários aspectos da situação e das diversas estratégias que podem ser exploradas, levando o aluno a desenvolver uma apreciação correta da Matemática e do pensamento matemático.

Oliveira, Segurado e Ponte (1996), acreditam que a investigação Matemática designa um tipo de atividade em que se enfatizam processos matemáticos tais como procurar regularidades, formular, testar, justificar e provar conjecturas, refletir e generalizar. 
Assim, por meio desse processo o aluno pode se sentir mais próximo de um matemático, e discutir com seus colegas suas ideias, colocar suas próprias questões e assim estabelecer que caminho irá seguir.

Nesse contexto, os alunos devem aprender por si próprios as ideias matemáticas e devem ser capazes de identificar padrões, fazer generalizações e usar experiências e observações para formular conjecturas. Também devem aprender a usar contraexemplo para mostrar que uma conjectura é falsa, fatos conhecidos e argumentos lógicos, assim como devem ser capazes de distinguir argumentos válidos de argumentos não válidos.

Portanto, o aluno aprende quando mobiliza os seus recursos cognitivos e afetivos com vista a atingir um objetivo. Logo, "ao requerer a participação do aluno na formulação das questões a estudar, essa atividade tende a favorecer o seu envolvimento na aprendizagem". (PONTE; BROCADO; OLIVEIRA, 2003, p. 23).

Nesse contexto, o PCN de Matemática (BRASIL, 1998) incentiva um trabalho que conduza o aluno a construir conhecimentos por meio da reflexão, pois o fato dele ser estimulado a questionar sua própria resposta, a questionar o problema, a transformar um dado problema numa fonte de novos problemas, a formular problemas a partir de determinadas informações, a analisar problemas abertos - que admitem diferentes respostas em função de certas condições -, evidencia uma concepção de ensino e aprendizagem não pela mera reprodução de conhecimentos, mas pela via da ação refletida que constrói conhecimentos.

\section{ALGUMAS CONSIDERAÇÕES}

A sociedade tem atribuído à escola o desafio de preparar com qualidade o cidadão para resolver os problemas que a cada dia mais nela se apresentam. Logo, é preciso que sejam reforçadas as reflexões que valorizam as iniciativas de ruptura paradigmática nos processos de ensinar e aprender que, acima de tudo, devem ter compromisso com a formação de cidadãos reflexivos, críticos e com condições de continuar a aprender e a produzir conhecimentos socialmente relevantes. 
Acredita-se que o compromisso social da educação é imensurável, sendo necessário que o professor se assuma como pesquisador de sua prática pedagógica, questionando o seu saber e buscando respostas por meio de pesquisas realizadas no cotidiano de suas atividades docentes que se constituam num continuum.

Nesse entendimento, o percurso traçado para realizar essa pesquisa, procurou responder à problemática principal, que consistia em refletir por meio de uma investigação bibliográfica se as práticas de ensino: resolução de problemas e investigação matemática, oriundas da Educação Matemática e usadas pelos professores de Matemática, auxiliam os alunos a enfrentarem as novas realidades tecnológicas e os desafios da sociedade desse mundo, mais complexo e globalizado.

De modo geral, entende-se que cada professor pode e deve fazer uso do que há de bom nas práticas de ensino para o preparo e aplicação de suas aulas, pois cada grupo de alunos apresenta características diferenciadas o que exige práticas de ensino, também diferenciadas.

É necessário pontuar que mesmo que o professor apresente um bom conhecimento dos conceitos matemáticos a ser ensinado, muitas vezes ele não consegue realizar sua transposição didática. Pois, uma coisa é conhecer a teoria e outra, muito diferente, é colocá-la em prática.

D'Ambrósio (2007) explica que no momento de busca do entendimento da teoria é que se toma a decisão de adotar ou não o seu conceito. Corroborando com D'Ambrósio (1996), Fiorentini e Miorim (1990), entre outros, afirmam que alguns dos problemas enfrentados no processo de ensino e aprendizagem, podem ser resolvidos com uma construção de valores adquiridos pelo professor, e não apenas com mudanças de currículo.

Portanto, o que se espera do professor é que ele tenha domínio dos conhecimentos sobre aquilo que pretende ensinar, pois se entende que a teoria e a prática devem caminhar juntas, visto que elas são indissociáveis. Nesse entender, é necessário que os professores tenham conhecimento das práticas de ensino que se propõem desenvolver. 
Segundo D'Ambrósio (1996), Paiva (1997) e Smole (2000), há a necessidade de se efetuar uma articulação entre a teoria e a prática, pois para que os professores consigam construir um processo de ensino e aprendizagem de qualidade, capaz de fazer com que os alunos se apropriem dos conhecimentos desejados, é necessário não só uma boa formação inicial e continuada dos mesmos como, também, um vasto número de suportes os quais incluam bons livros didáticos, artigos científicos em periódicos e anais de congresso além de manuais de professor compatíveis com suas necessidades.

O PCN de Matemática (Brasil, 1998, p. 21) confirma que a falta de uma formação profissional qualificada, as restrições ligadas às condições de trabalho, a ausência de políticas educacionais efetivas e as interpretações equivocadas de concepções pedagógicas afetam o processo de ensino e aprendizagem.

Nesse sentido, é pertinente que os professores tenham subsídios que Ihes permitam serem professores conscientes dos desafios e das possibilidades da sua futura profissão, com os saberes necessários para se tornarem profissionais competentes para atuarem na realidade escolar atual.

Convém acrescentar que a Educação Matemática, promove um ensino mais significativo, na tentativa de superar as lacunas existentes perante as exigências da sociedade atual e, dentro de sua perspectiva, os alunos são levados a raciocinar sobre a necessidade de construir novos conceitos e processos, bem como a de associar a outros já existentes. Portanto, apresenta significados nas atividades, proporcionando aos alunos - cidadãos do futuro - meios para cumprirem as exigências do mundo globalizado.

Logo, entende-se que quanto maior for a quantidade de informações sobre algumas práticas de ensino que se fazem presentes nas salas de aula de Matemática, mais subsídios metodológicos os professores terão para auxiliá-los na construção do processo de ensino e aprendizagem.

As reflexões traçadas até aqui permitem afirmar que as práticas de ensino têm papel importante no interior das escolas no que tange à formação dos alunos perante os desafios impostos pela sociedade atual. 
Nesse contexto, percebe-se que ensinar Matemática através da resolução de problemas é uma prática de ensino que está de acordo com o PCN de Matemática (BRASIL, 1998), visto que ela apresenta seu foco voltado à ação por parte dos alunos. Ressalta-se que nessa prática de ensino, cabe ao professor o papel de observador, organizador e motivador para o objetivo que se quer alcançar, pois ao professor cabe inventar problemas interessantes cuja solução contemple o conceito matemático que se deseja estudar.

Nesse sentido, a discussão sobre o ensino da matemática através da resolução de problemas pode se tornar mais uma ferramenta para os educadores desde que compreendida e que haja uma busca para aperfeiçoá-la na sua prática individual, não deixando relegada a mais uma teoria sem aplicação prática.

Logo se entende que, a prática resolução de problemas proporciona ao educando meios de estabelecer o conhecimento necessário para auxiliá-lo no estudo de outros ramos da Matemática e de outras disciplinas, visando uma interdisciplinaridade dinâmica e efetiva, por meio do desenvolvimento de habilidades que favorecem a construção do pensamento lógico, preparando o aluno para estudos mais avançados em outros níveis de escolaridade.

As leituras traçadas até aqui, também permitem afirmar que as atividades investigatórias proporcionaram ao estudante, meios de estabelecer o conhecimento necessário para auxiliar o estudo de outros ramos da Matemática e de outras disciplinas.

Mas, cabe ressaltar que é natural que atividades investigativas podem gerar, a princípio, um desconforto, pois o caráter aberto de uma atividade investigativa torna difícil a antecipação do repertório completo das possíveis respostas dos estudantes.

Mesmo com esse desconforto inicial, as atividades matemáticas que envolvem um trabalho investigativo, com o reconhecimento da situação, a formulação de questões, a formulação de conjecturas, o seu teste e refinamento e a argumentação, demonstração e avaliação do trabalho realizado, tornam-se mais atrativas para os alunos e são relevantes porque podem proporcionar grande desafio aos alunos. Entretanto, também são apontadas como desafio aos sistemas educativos atuais. 
Espera-se que as atividades investigativas desenvolvidas proporcionem aos alunos uma experiência matemática positiva. Pois, as investigações introduzidas na aula de matemática podem desestabilizar concepções e crenças de matemática e de aula de Matemática, bem como do papel de professores de Matemática.

Para encerrar é relevante frisar que a escola tem por escopo formar estudantes capazes de compreender o mundo e dele participar de forma crítica, criativa e ativa. Portanto, a proposta de situar o ensino da Matemática nos aportes das práticas de ensino resolução de problemas e investigação matemática justifica-se pela importância de implantar nos estudantes aptidões que são úteis para sua compreensão de mundo e, assim apropriar-se do que lhe é ensinado.

\section{REFERÊNCIAS}

ALLEVATO, N. S. G. Associando o Computador à Resolução de Problemas Fechados: Análise de uma Experiência. 2005. 370 f. Tese (Doutorado em Educação Matemática) - Instituto de Geociências e Ciências Exatas, Universidade Estadual Paulista Julio de Mesquita Filho, Rio Claro, 2005.

ARCAVI, A. E em matemática, o que constroem aqueles que instruem. Substratum: temas fundamentais em psicologia e educação. Porto Alegre: Artmed, v. 2, n. 5, 1998.

BICUDO, M. A. V.; GARNICA, A. V. M. Filosofia da Educação Matemática. Belo Horizonte: Autêntica, 2005.

BRASIL. Ministério da Educação. Parâmetros Curriculares Nacionais: Matemática. Brasília: MEC/SEF, 1998.

CHAPMAN, O. Metaphors in the teaching of mathematical problem solving. Educational Studies in Mathematics, n. 32, v. 3, p.201-228, 1997.

CHRISTIANSEN, B.; WALTHER, G. TASK. In: CHRISTIANSEN, B.; HOWSON, AG AND OTTE, M. (Eds.). Perspective son mathematics education, p. 243-307. Dordrecht: D. Reidel, 1986.

CONTADOR, P. R.Matemática, uma breve história. Vol. 1. 2 ed. São Paulo: Editora Livraria da Física, 2006.

D’AMBROSIO, U. Da realidade à ação. São Paulo: Summus, 1986.

KILPATRICK, J. Fincando estacas: uma tentativa de demarcar a Educação Matemática como campo profissional e científico. Zetetiké, Campinas, vol. 4, no 5, 1996.

KRULIK, S.; RUDNICK, J. A. Problem-Driven Math: Applying the Mathematics Beyond Solutions. Chicago: McGraw-Hill, 2005. 
LAMPERT, M. When the problem is not the question and the solution is not the answer: Mathematical knowing and teaching. American Educational Research Journal, 29-63, 1990.

MACHADO, N. J. Matemática e Realidade: análise dos pressupostos filosóficos que fundamentam o ensino da matemática. São Paulo: Cortez, 1997.

MASON, J. Resolução de problemas matemáticos no Reino Unido: Problemas abertos, fechados e exploratórios. In: ABRANTES, P; LEAL, L. C AND PONTE, J. P., 1996.

MIGUEL, A; GARNICA, A. V. M; IGLIORI, S. B. C.; D’AMBRÓSIO, U.A educação matemática: breve histórico, ações implementadas e questões sobre sua disciplinarização. Revista Brasileira de Educação Matemática. Set/Out/Nov/Dez 2004.

NATIONAL COUNCIL OF TEACHERS OF MATHEMATICS.Curriculum and Evaluation Standards for School Mathematics. Reston: NCTM, 1989.

. Professional Standards for Teaching Mathematics. Reston: NCTM, 1991.

. Assessment Standards for School Mathematics. Reston: NCTM, 1995.

. Principles and Standards for School Mathematics. Reston: NCTM, 2000.

OLIVEIRA, H. M., SEGURADO, M. I.; PONTE, J. P. Explorar, investigar e discutir naaula de Matemática. In: ROQUE, A.; LAGARTO, M. J. (Orgs.). Actas do ProfMat 96. p. 207-213. Lisboa: APM, 1996.

ONUCHIC, L. DE LA R. Ensino-aprendizagem de Matemática através da resolução de problemas. In: BICUDO, M. A. V. Pesquisa em Educação Matemática: concepções \& perspectivas. São Paulo: UNESP, cap. 3, p. 199-218,1999.

- Novas Reflexões sobre o ensino-aprendizagem de matemática através da resolução de Problemas. In: BICUDO, M. A.; BORBA, M. (orgs). Educação Matemática - pesquisa em movimento, São Paulo, Editora Cortez, 2003.

A Resolução de Problemas e o trabalho de ensino-aprendizagem na construção dos números e das operações definidas sobre eles. In: ENEM, 8., 2004, Recife. Anais do VIII Encontro Nacional de Educação Matemática. Recife: UFP, 2004.

ONUCHIC, L. R.; ALLEVATO, N. S. G. Novas Reflexões sobre o ensino-aprendizagem de matemática através da resolução de Problemas. In: BICUDO, M. A. V.; BORBA, M. (Org.) Educação Matemática: pesquisa em movimento. São Paulo: Editora Cortez, 2005.

POLYA, G. A arte de resolver problemas: um enfoque do método matemático. Tradução e adaptação: Heitor Lisboa de Araújo. Rio de Janeiro: Interciência, 1949.

PONTE, J. P. Didáticas específicas e construção do conhecimento profissional. In: TAVARES; PEREIRA, J. A.; PEDRO, A. P.; SÁ, H. A (Eds.). Investigar e formar em educação: Atas do IV Congresso da SPCE, p. 59-72. Porto: SPCE, 1999.

.Investigar, ensinar e aprender. Atas do ProfMat, CD-ROM, p. 25-39, Lisboa: APM, 2003.

PONTE, J. P.; BROCARDO, J.;OLIVEIRA, H. Investigações Matemáticas na Sala de Aula. Belo Horizonte: Autêntica, 2003.

PROJECT 2061. Benchmarks for science literacy. New York, NY: Oxford University Press, 1993. 
SCHROEDER, T.; LESTER Jr., F. Developing Understanding in Mathematics via Problem Solving.In: TRAFTON, P. R.; SHULTE, A. P. (Ed.) New Directions for Elementary School Mathematics. National Council of Teachers of Mathematics, 1989.

VAN DE WALLE, J. Elementary and Middle School Mathematics. New York: Logman, 2001.

WOOD, T. Events in learning mathematics: Insights from reaserch in classrooms. Educational Studies in Mathematics, 1996. 